\title{
Report of the Editor of the American Political Science Review, 1996-97
}

\author{
Ada W. Finifter, Michigan State University
}

The 1996-97 academic year was a busy one at the Review. The flow of manuscripts continues to grow, and we continue to strive for a review procedure that is as efficient as possible, and reviews and a journal that are both of the highest possible quality. As always, the Review benefits from the efforts of many people. We continue to use the same procedures for selection of reviewers that were described in last year's report (Finifter 1996). These depend heavily on preliminary analyses by APSR interns (all advanced graduate students) of all newly submitted papers and the subsequent evaluation and advice of members of the Editorial Board. ${ }^{1}$ In addition, in each of the last two years, approximately 1,000 different political scientists have donated their time and intellectual energies to the APSR's peer review process. These anonymous reviewers make an incalculable contribution to the quality of papers in the Review and are frequently acknowledged by authors. The names of all external reviewers are listed in each December's issue. ${ }^{2}$

As anticipated last year, three new members were added to the Editorial Board this year to increase the depth and breadth of our collective expertise, and the Board now numbers thirty-three. The names of Board members and the interns and staff for both the articles section and book review sections of the Review can be found in each issue.

\section{Submissions}

Table 1 demonstrates that the number of submissions continues to increase, although the increase was very small this past year. ${ }^{3}$ Of the 540 manuscripts received, 391 were "original" or new manuscripts, and 149 were resubmissions of revised articles. Of the 391 new manuscripts, 22 were rejected for being submitted incorrectly. An "incorrect submission" is defined as one that will involve at least some rewriting to com- ply with editorial requirements for submission, so that a correct submission will be different from the one that is being rejected (for example, a paper that is too long to be reviewed and needs to be shortened). For submissions that are flawed in some minor sense (no abstract, only one copy, pages missing or illegible), the author is contacted to correct the problem, but the manuscript is held for review and is still counted as only one submission. Therefore, 369 manuscripts were started through the review process. Of these, 8 were rejected in-house as inappropriate for the APSR rather than being sent out for review.

The rather small increase over 1995-96, and the decline in the number of new manuscripts submitted from 420 in 1995-96 to 391 in

\section{TABLE 1 APSR Submissions (Total Manuscripts Received)}

\begin{tabular}{ll}
\hline $1996-97$ & 540 \\
$1995-96$ & 533 \\
$1991-95$ (Average) & 485 \\
$1986-91$ (Average) & 426 \\
$1994-95$ & 495 \\
$1993-94$ & 480 \\
$1992-93$ & 487 \\
$1991-92$ & 479 \\
$1990-91$ & 438 \\
$1989-90$ & 428 \\
$1988-89$ & 447 \\
$1987-88$ & 391 \\
$1986-87$ & 427 \\
\hline
\end{tabular}

*August 15, 1996-August 14, 1997 including the July 15-August 14 period when new manuscripts were not accepted for review. Includes resubmissions.

Sources: Data for 1991-95, and average for 1985-91 is taken from Powell (1995, Table 1). Average for 1991-95 are calculated from the same source. Individual year data for 1986-87 to 1990-91 are taken from Patterson, Bruce, and Crone (1991, Table 1).
1996-97, is the result of an experimental one-month moratorium on new submissions (between July 15 and August 14, 1997) that was introduced in cooperation with several other political science journals (the American Journal of Political Science, the Journal of Politics, Political Research Quarterly, and Polity). The moratorium was widely publicized in the "Editor's Notes" of both the March and June issues of the Review, in the March issue of $P S$, and on the APSR home page on the Internet, and it appears that most potential authors were aware of it and correctly informed about it. ${ }^{4}$

Twenty-seven of the manuscripts received during 1996-97 came in during the new paper moratorium period, and seventeen were resubmissions, which were processed normally. The ten new submissions were processed after the moratorium period. During the same month in 1996, when all manuscripts were processed normally, 49 manuscripts were received, 37 of which were new submissions. Thus, it appears that the moratorium resulted in a decline of approximately 27 new manuscripts, almost exactly the difference between 1995-96 and 1996-97 in new submissions. We assume that most of the "missing" papers will appear during Fall 1997 and later and that the submission count for next year will be correspondingly increased. Nevertheless, despite the shortfall in new manuscripts, enough revised articles came in to boost the overall total of manuscripts received over last year's total. ${ }^{5}$

We expect to add a part-time assistant to the APSR staff in the coming months so that we will be able to continue processing manuscripts as efficiently as possible. However, since there will remain only one Editor, I am also exploring ways in which the role of the Editorial Board may be expanded so that delays in decisionmaking can be kept to a minimum.

The moratorium was very success- 
ful in decreasing the work load of the Review editorial office during the summer period when staff take vacations and permitted the Editor to do some catching up on manuscript decisions and other tasks.

Between mid-August 1996 and mid-August 1997, a total of 673 different manuscripts passed over my desk at some stage of the process, almost all of them more than once. In addition to selection of reviewers or other disposition on all 540 incoming manuscripts, and 400 decisions on this group, 133 decisions were made on manuscripts submitted during the last reporting year (i.e., prior to August 15, 1996). One hundred and fourteen manuscripts received prior to August 15, 1997 are still in process as I write this report (September 10, 1997), and 44 additional manuscripts have been received since August 15.

\section{Field Classification of Submitted Manuscripts}

For major field coding, we use the categories American Politics and Public Policy, Comparative Politics, International Relations, Normative Political Theory, Methodology, and Formal Theory of General Political Processes (abbreviated in some tables below simply as Formal Theory); the last is used only for papers that consist entirely of formal analysis (i.e., do not include empirical testing) and are too general to be assigned to one of the substantive fields. Since last year, we have not been automatically considering formal theory papers as a different field of the discipline, since papers using this analytic method are now found with increasing frequency in most substantive fields. Similarly, the Methodology field contains only general methodological papers which cannot be assigned to a substantive field, such as those advocating a new statistical method or offering conceptual analyses of research methods or approaches that do not focus specifically on a particular substantive field.

In addition to coding manuscripts by general substantive field, we also code them according to analytic method, which has five categories:

\section{TABLE 2 Distribution of Manuscripts Submitted to the APSR, August 15, 1996-August 14, 1997 by Subfield, Type of Analysis, and Manuscript Status}

\begin{tabular}{|c|c|c|c|c|}
\hline \multirow{2}{*}{$\begin{array}{c}\begin{array}{c}\text { Subfield and Type of } \\
\text { Analysis }\end{array} \\
\text { American Politics }\end{array}$} & \multicolumn{2}{|c|}{ All Manuscripts } & \multicolumn{2}{|c|}{$\begin{array}{c}\text { Original } \\
\text { Submissions }\end{array}$} \\
\hline & & & & \\
\hline Formal and Quantitative & 14 & $2.59 \%$ & 10 & $2.56 \%$ \\
\hline Formal & 11 & 2.04 & 8 & 2.05 \\
\hline Interpretive, Conceptual & 10 & 1.85 & 9 & 2.30 \\
\hline Quantitative & 177 & 32.78 & 125 & 31.97 \\
\hline Small N & 1 & .19 & & \\
\hline Subfield total & 213 & $39.44 \%$ & 152 & $38.88 \%$ \\
\hline \multicolumn{5}{|l|}{ Comparative Politics } \\
\hline Formal and Quantitative & 6 & $1.11 \%$ & 5 & $1.28 \%$ \\
\hline Formal Analysis & 14 & 2.59 & 9 & 2.30 \\
\hline Interpretive, Conceptual & 23 & 4.26 & 19 & 4.86 \\
\hline Quantitative Analysis & 74 & 13.70 & 46 & 11.76 \\
\hline Small N & 15 & 2.78 & 14 & 3.58 \\
\hline Subfield total & 132 & $24.44 \%$ & 93 & $23.78 \%$ \\
\hline \multicolumn{5}{|l|}{ International Relations } \\
\hline Formal and Quantitative & 5 & $0.93 \%$ & 3 & $.77 \%$ \\
\hline Formal Analysis & 15 & 2.78 & 10 & 2.56 \\
\hline Interpretive, Conceptual & 11 & 2.04 & 9 & 2.30 \\
\hline Quantitative Analysis & 38 & 7.04 & 22 & 5.63 \\
\hline Small $N$ & 1 & .19 & 1 & .26 \\
\hline Subfield total & 70 & $12.96 \%$ & 45 & $11.52 \%$ \\
\hline \multicolumn{5}{|l|}{ Normative Theory } \\
\hline Interpretive, Conceptual & 85 & $15.74 \%$ & 70 & $17.90 \%$ \\
\hline Subfield Total & 85 & $15.74 \%$ & 70 & $17.90 \%$ \\
\hline \multicolumn{5}{|l|}{$\begin{array}{c}\text { Formal Theory of General } \\
\text { Political Processes }\end{array}$} \\
\hline Formal Analysis & 29 & $5.37 \%$ & 20 & $5.11 \%$ \\
\hline Subfield Total & 29 & $5.37 \%$ & 20 & $5.11 \%$ \\
\hline \multicolumn{5}{|l|}{ Methodology } \\
\hline Formal and Quantitative & 1 & $.19 \%$ & 1 & $.26 \%$ \\
\hline Interpretive, Conceptual & 5 & $.93 \%$ & 5 & 1.28 \\
\hline Quantitative Analysis & 5 & .93 & 5 & 1.28 \\
\hline Subfield total & 11 & $2.05 \%$ & 11 & $2.81 \%$ \\
\hline Total Manuscripts & 540 & $100.00 \%$ & 391 & $100.00 \%$ \\
\hline
\end{tabular}

Quantitative, Formal, Both Quantitative and Formal, Small N Hypothesis Testing, and Conceptual or Interpretive. ${ }^{6}$ The latter refers to textual analyses using no quantitative or formal methods. The fields of American Politics and Public Policy, Comparative Politics, and International Relations use all five analytic method codes. Methodology can theoretically use all as well, but since the number of papers we receive in this field is quite small, not all analysis categories are used. Normative theory papers generally use conceptual or interpretive (including tex- tual) analysis only. All Formal Theory of General Political Processes papers are classified as using Formal Analysis as their analytic method. By definition, these papers are not quantitative; if they used data they would be classified as American, Comparative, or International Relations depending on the data source. The use of two codes for each paper permits reporting on the basis of analytic method as well as substantive area.

Table 2 shows the distribution of manuscripts received by both field and analytic method, for both total 


\section{TABLE 3}

\section{Manuscripts Received by Field, 1985-97}

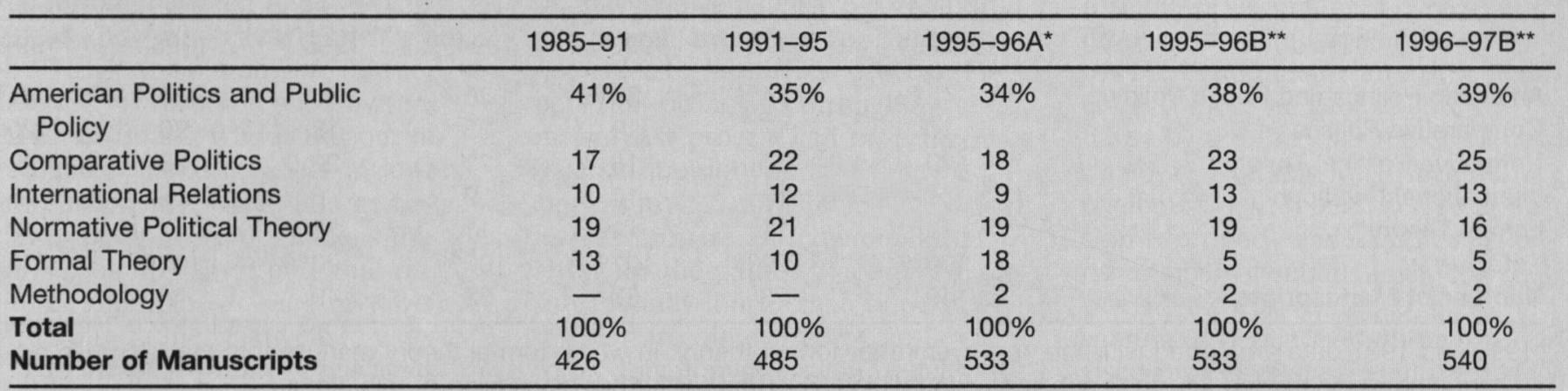

*1995-96A allocates formal theory papers in all fields to "Formal Theory" category for consistency with previous editorial reports.

**1995-96B and 1996-97B allocates formal theory papers to their substantive field (American Politics, Comparative Politics, or International Relations) whenever possible.

Sources: Average for 1985-91 from Powell (1995, Table 1). Average for 1991-95 calculated from same source.

submissions and only for those manuscripts that were original submissions (not including revisions). Among those manuscripts submitted to the Review, American Politics papers are still heavily quantitative. Quantitative analyses also dominate in Comparative Politics, but to a much lesser degree; and while quantitative analyses are still the majority in International Relations, other methods of analysis are almost as important in this, the most analytically heterogeneous of the fields.

The fact that the percentage distributions in both columns of Table 2 are so alike suggests that papers in all fields fare remarkably similarly in terms of being invited for revision. Since I make no attempt to establish quotas or goals by either field or analytic method, and my decisions are grounded in the reviews, this also suggests that reviewers in all fields use similar or comparable standards of evaluation. (Data presented below also indicate that acceptance rates are very similar across fields.)

Data presented in Table 3 suggest relative stability in the distribution of manuscripts submitted by major field over recent years. While there may appear to be a trend toward submission of more comparative and international relations manuscripts, this is undoubtedly caused largely by the change in coding of formal theory papers. By coding them according to their substantive field (American,
Comparative, or International Relations) whenever possible, the submissions categorized in those fields are bound to increase, just as the coding causes an apparent (but not real) decline in Formal Theory submissions. The only field whose change in submission level is unaffected by this is Normative Theory, which declined somewhat in 1996-97. It seems doubtful that this small difference is a meaningful change that will persist over time. Interestingly, Normative Theory has a very slightly higher acceptance rate than most other fields, so even if this decline in submissions were real, it would, at least in the short term, not have important implications for the relative balance of papers appearing in the Review.

While the APSR is still dominated by articles in American Politics, over a third of our submissions are now in Comparative Politics and International Relations. This trend extends the utility of the Review to a larger number of scholars both in and outside the United States.

\section{Manuscripts Published}

Table 4 shows field distributions for manuscripts published since 1985. While random factors relating to timing of submissions cause some annual discontinuities that are not meaningful, it seems clear that the Review has gotten increasingly di- verse, and possibly more representative of the discipline as a whole, in recent years. As compared to ten years ago, representation of the American Politics field is lower, and representation of Comparative Politics, Normative Political Theory, and International Relations have all increased. ${ }^{7}$

\section{Turnaround Time}

As submissions increase, keeping turnaround time low becomes ever more difficult, but we continue to work very hard toward this goal so that authors are not held up in publication of their research. Table 5 shows four measures of mean time spent in various stages of the Review editorial process for the last two years. These data include only those manuscripts on which a decision has been made, and the estimates of time intervals for 1996-1997 may therefore be low since papers that are still awaiting decisions may include some that have been in process longer than average. ${ }^{8}$ Data from last year are provided because the comparable table in my last Annual Report (Finifter 1996) was necessarily incomplete since many manuscripts received during that year were still in process at the time the report was written.

The measure from receipt to referee assignment indicates how quickly manuscripts are mailed to reviewers 
TABLE 4

Manuscripts Published by the APSR, by Field, 1985-97

\begin{tabular}{|c|c|c|c|c|c|c|c|}
\hline Field & $1985-91$ & 1992 & 1993 & 1994 & 1995 & 1996 & 1997 \\
\hline Comparative Politics & 16 & 17 & 19 & 23 & 18 & 20 & 20 \\
\hline International Relations & 10 & 13 & 14 & 9 & 6 & 16 & 25 \\
\hline Formal Theory ${ }^{\star}$ & 13 & 11 & 11 & 11 & 18 & $9^{*}$ & $6^{\star}$ \\
\hline Total & $100 \%$ & $99 \%$ & $101 \%$ & $100 \%$ & $100 \%$ & $100 \%$ & $100 \%$ \\
\hline
\end{tabular}

*1996 and 1997 data are coded with the new system for formal theory, in which formal theory manuscripts that also use empirical data are distributed into their substantive subfields. See text for further discussion of this change.

after receipt in our office. This involves several operations: logging in of manuscripts, assignment to an intern, reading and preparation of an analytical summary by the intern, intern research into potential reviewers who have done related work, Editor's review of intern's written package, e-mailing of author's abstract and intern's work to appropriate Editorial Board members, receipt of responses advising on reviewers from members of the Board, decisions by Editor on reviewer panel, and preparation and mailing of letters and packages for reviewers. That we accomplish all of this in an average time of a week and a half is a clear testimonial to the dedication of $A P S R$ 's interns and Editorial Board.

The measure from assignment to last review indicates how quickly reviewers respond, the persistence of our reminder process, and how quickly we select substitute reviewers for those who tell us they are unable to review or who do not respond.
For papers that receive poor reviews from the first two reviewers, this represents the time it takes for only these first two reviews to come in, since papers will be rejected if both of the first two reviewers clearly so advise. For papers with more positive reviews, this time covers the period until the third review arrives. Time until the last review can be very low when the initial reviewers all respond promptly, but it can easily be doubled or tripled by reviewers who are very late or unresponsive. In such cases, papers may not go out to substitute reviewers until many weeks into the process.

As described in last year's report (Finifter 1996, 763-64), we have a very active reviewer reminder process, including postcards sent before the due date of a review, faxes, and e-mails. In general, most reviewers are extremely conscientious and many keep in touch with us by email if they expect their reviews to be delayed. Nevertheless, we have only limited control over this stage in the process. Delays are frequently unavoidable as reviewers' own research and other work obligations, university break periods, etc. delay or distract reviewers. Reviewer turnaround time can be a particular problem in areas where there are relatively few qualified reviewers, e.g., in some very technical fields, or for papers which require specialized area knowledge that is not very widespread. Papers in Comparative Politics seem to be particularly subject to late review problems since many potential reviewers are often away from their home institutions doing field research. If a particular area of research is small but has very active researchers, it is easy to run out of suitable reviewers since each manuscript that comes in "uses up" multiple reviewers. We maintain extensive files of reviewers and each day print a report from our database that provides the names of all persons currently doing reviews or to

\section{TABLE 5}

\section{Elapsed Time in the APSR Review Process, by Year of Submission, for Manuscripts Decided by August 14, 1997*}

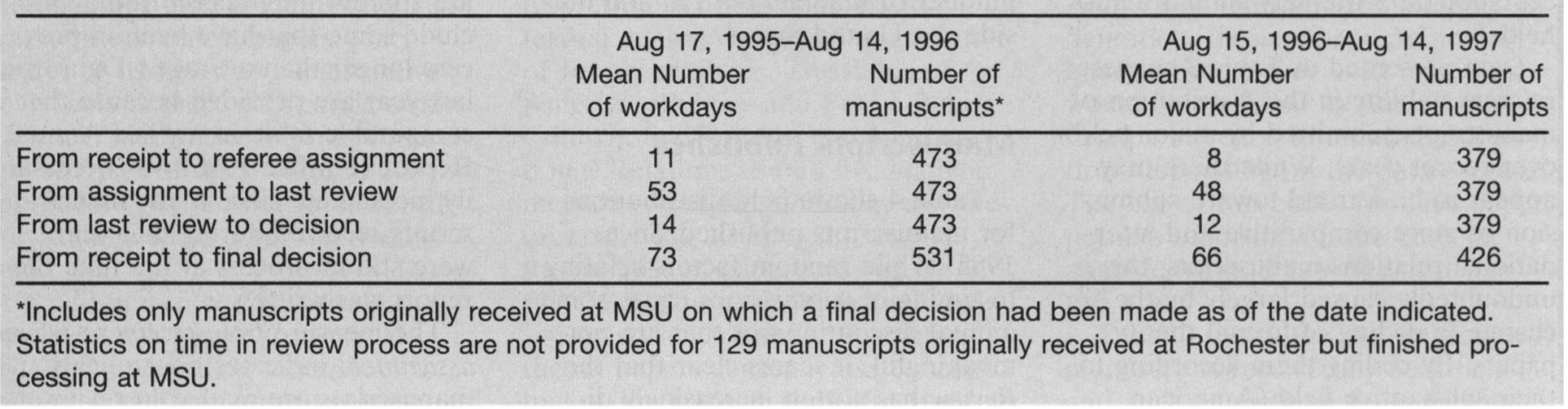


whom manuscripts have been sent, as well as those who are in a "resting period" between reviews. This lets us know who is currently "available" (in principle anyone in our database or recommended by the Editorial Board, who is not on the list) and helps us to select reviewers more efficiently. Using a large reviewer pool, as we do, lessens the burden on any given potential reviewer and helps us keep reviewer turnaround time relatively low.

The measure from last review to decision indicates the time the Editor takes to make decisions after the final review has arrived (either two where both indicate rejection or three with more positive reviews). This includes study of the reviews and of the paper if warranted by the reviews, making an editorial decision, and composing and mailing a letter to the author.

Papers for which reviewers unanimously advise rejection can be processed very quickly. Initial submissions with consistent supportive reviews that nevertheless suggest significant revision are also handled relatively promptly. Papers that have mixed reviews (the vast majority) take much longer to evaluate, and the Editor's decision pile can sometimes become uncomfortably high. (It has never been higher than the Editor, however, despite her relatively diminutive stature.) Manuscripts with mixed reviews can be very time-consuming to bring to completion because they usually require an independent editorial judgment about which reviews are most useful and which of the conflicting pieces of advice should be followed, and sometimes lead to further consultation with other reviewers or members of the Editorial Board. Papers that are ready for a publication decision after an initial or second revision also sometimes get backed up, especially when the later reviews suggest that more work is required to bring a paper to $A P S R$ standard.

The measure from receipt to final decision is the mean number of days in the process for all manuscripts received. This figure is not necessarily equivalent to the sum of the previous measures because it also includes papers that are judged to be inappropriate for the Review or whose quality is not sufficiently high to put them into the review process, or that involve extensive correspondence with authors even if they are not put into the review process. $\mathrm{Pa}$ pers that do not go through a normal review process can nevertheless take substantial editorial time because I myself must review them and usually prepare an individualized letter for the author. Papers that are substantially longer than our guidelines or are discovered by an intern to be nonanonymous can be handled more expeditiously. Submissions that appear to overlap significantly with an already published paper by the same author can take up extraordinary amounts of time as they may involve substantial correspondence with the author and/or comparison of the submitted manuscript with other publications. ${ }^{9}$

Despite the fact that the overall numbers are relatively low, measures of central tendency can obscure wide ranges, and some papers take an uncomfortably long time to come to decision for one reason or another. Processing of papers with conflicting reviews often takes longer than I would like, but I do strive to get decisions out as quickly as possibleconsistent, of course, with a careful and conscientious review process. ${ }^{10}$

\section{Acceptance Rates}

The Association budget provides the Editor with a fixed number of pages for the Review. Consequently, as the number of submissions continues to rise, the acceptance rate will necessarily decline..$^{11}$ It is the received wisdom that the Review publishes only about $10 \%$ of papers received. While this is reasonably close to accurate, it is actually somewhat on the high side, considering the approximately $10 \%$ increase in submissions over the past two years. (A variety of comparisons can be made with specific years or averages over more than one year; see Table 1). Increasingly, also, papers go through more than one revision to satisfy reviewers and to achieve sufficient support to persuade the Editor that a paper is ready for publication in the Review.

I have tried to calculate an accep- tance rate that is as true as possible. Acceptance rates calculated using a formula of acceptances over total number of submissions (i.e., using for the denominator numbers analogous to those in Table 1) are deflated by the fact that the "total number of submissions" includes resubmissions. While each resubmission is properly included in the "total number of submissions" for analysis of editorial workload, a given submitted paper, even though revised once or twice, should probably not be counted two or three times in the denominator of the acceptance rate formula. Another complication is deciding on a time period: which manuscripts to include and which editorial decisions to include. Manuscripts invited for revision often flow over two or more reporting periods (e.g., an original could have been submitted late in academic year 1995-96, decided upon in early 1996-97, come back in as a revision in 1997-98, etc.). Of course, at any given time, many manuscripts invited for revision will not have come back yet or may be awaiting a decision. Since it is also likely that there will be year-to-year variation depending on random factors associated with submissions and perhaps systematic factors such as existence of a substantial backlog (which is not an issue at $A P S R$ at present), the most stable figures are probably those for the longest possible meaningful time period. For these reasons, I present data for all manuscripts submitted originally to the MSU office (again, these data do not include any manuscripts sent originally to Rochester, even though their revisions may have been processed here). ${ }^{12}$

Table 6 shows the distribution of decisions, for all manuscripts submitted as new since mid-August 1995, at each of three stages of submission: the original submission, when a paper is new to the Review, and the first and second revision stages. The table includes all manuscripts for which decisions were made by midAugust 1997. The second and third columns are each based on papers also included in the prior column's figures.

As the data for new submissions indicate, it is very rare for a paper to be accepted on the first round. Also, 
TABLE 6

Manuscript Decisions by Review Stage for All Manuscripts Sent as New Submissions to MSU Office

\begin{tabular}{lccc}
\hline & $\begin{array}{c}\text { New } \\
\text { Submissions }\end{array}$ & $\begin{array}{c}\text { First } \\
\text { Revision }\end{array}$ & $\begin{array}{c}\text { Second } \\
\text { Revision }\end{array}$ \\
\hline Reject & $65.0 \%(507)$ & $39.8 \%(39)$ & $33.3 \%(5)$ \\
Revise \& Resubmit & $25.3(197)$ & $28.6(28)$ & $6.7(1)$ \\
Accept & $1.4(11)$ & $31.6(31)$ & $60.0(9)$ \\
Other & $8.3(65)$ & $0(0)$ & $0(0)$ \\
$\%(\mathrm{~N})$ & $100.0 \%(780)$ & $100.0 \%(98)$ & $100.0 \%(15)$ \\
\hline
\end{tabular}

Note: Includes only manuscripts originally received at MSU (i.e., were not revisions originally submitted at Rochester). All 98 first revision papers therefore came from the new submission round, and all second revision papers came from the first revision round.

unfortunately, a substantial minority of papers are not accepted even after revision (although for many of these, the Editor's first decision letter may not have been very encouraging). Although we do go to second revisions on a minority of first revision papers, the "accept" line shows that the vast majority of published papers are accepted on the first or second round, and that a paper that is revised a second time has a better than even chance of being accepted. ${ }^{13}$

That reviews are still too critical for many manuscripts to be accepted even after revision suggests that the number of papers that are invited for revision should not be increased. An interesting question is whether it should be decreased. At present, only about a quarter of original submissions are given "revise and resubmit" status. All of these show substantial promise and, generally, at least two of the three reviewers encourage revision. While we can see from the aggregate figures that many revisions will not be successful, since it is difficult to predict the fate of individual papers, my inclination is to be somewhat liberal in inviting revisions. At the same time, I try to be very clear in my letters to authors about the prospects of a revision being accepted for publication, telling them which of the original reviewers the paper will be returned to, and being somewhat differentially encouraging depending on the promise shown in the reviews. ${ }^{14}$ For many revise and resub- mit papers, I advise the authors that they should consider carefully the relatively uncertain nature of the process before deciding to commit additional time to APSR's review process by sending in a revision. Clearly, some authors are less pressed for time and for positive decisions than others are, and in a fairly uncertain process it seems reasonable that authors' own risk acceptance levels should play some role. Nevertheless, I do not want authors and their work to be tied up in our review process unnecessarily, nor to unnecessarily burden our reviewers. Therefore, over time I have been decreasing slightly the number of revise and resubmit invitations offered on the first round, accepting slightly more papers on the second round even where the level of reviewer support may leave something to be desired, and cutting down the number of papers that go to a second revision (which can also mean increasing the rejection rate on the second round).

The one positive aspect of maintaining a relatively low acceptance rate is that it enables us to avoid building up a large backlog of forthcoming articles, so that the papers we do accept are published relatively rapidly. At present (mid-September) we have a very comfortable backlog of about one issue, the December 1997 issue is in press, March 1998 is full and papers for that issue are being copyedited, and articles are being accepted for June.

\section{Acceptance Rates By Field}

Table 7 presents acceptance rates by field for all manuscript "chains" that began as original submissions at MSU. ${ }^{15}$ In general, although no consideration is given to field when making decisions, acceptance rates are very similar across all fields. The one exception is for Methodology, but the number of papers submitted has been relatively small. Especially in that case, but in some others as well, the small number of submissions (or at least manuscripts assigned to that category under our coding scheme) means that the acceptance rates are not very stable. For example, accepting one paper in the Methodology category would have lifted its acceptance rate above that of Formal Theory, accepting one more Formal Theory paper would have lifted its acceptance rate to the third highest, accepting one less Normative Theory paper would have moved its acceptance rate below that of International Relations, and accepting one less International Relations paper would have moved its rate to below that of American Politics. Therefore, the most important message of the table is not that rates are different among fields but that they are very similar. Sorting on analytic method rather than field, the acceptance rates are also close: Formal Analysis, 5.3\%; Quantitative Analysis, 7.4\%; Both Formal and Quantitative Analysis, 6.8\%; Interpretive or Conceptual Analysis, 6.2\%; Small N, 0 (a new code with only 14 original submissions so categorized). ${ }^{16}$

\section{Author Services}

Keeping turnaround time as low as possible and getting high quality reviews are important services to all scholars who submit manuscripts to the Review, and I have discussed above our results in those areas. Once articles are accepted, a new and different round of tasks begins.

The one issue backlog now provides enough time between acceptance and publication for us to be able to send copyedited versions of manuscripts to authors for their approval prior to printing. Under the 
TABLE 7

Acceptance Rates of Manuscripts by Field, for Manuscripts Submitted Since August 17, 1995 and Decided Upon by August 15, 1997

\begin{tabular}{lccc}
\hline \multicolumn{1}{c}{ Field } & $\begin{array}{c}\text { Number of } \\
\text { Original } \\
\text { Submissions }\end{array}$ & $\begin{array}{c}\text { Number of } \\
\text { Papers } \\
\text { Accepted }\end{array}$ & Acceptance Rate \\
\hline American Politics & 295 & 20 & $6.8 \%$ \\
Comparative Politics & 191 & 11 & $5.8 \%$ \\
Normative Theory & 141 & 11 & $7.8 \%$ \\
International Relations & 95 & 7 & $7.4 \%$ \\
Formal Theory & 41 & 2 & $4.9 \%$ \\
Methodology & 20 & 0 & $0 \%$ \\
Total & 783 & 51 & $6.5 \%$ \\
\hline
\end{tabular}

old system, where this did not happen, we were still able to make necessary corrections and changes on galley proofs. However, authors are happier, the system works more efficiently, and printing correction costs are lower when authors see copyediting in advance of printing. This system requires extra staff work at the copyediting stage but cuts down costs and corrections at the galley proof stage. In the near future, we will begin working toward a system of disk submission and some electronic copyediting. We will try very hard to meet the challenge of modernizing Review production while still retaining the marked advantages of old-fashioned substantive copyediting by skilled professionals. ${ }^{17}$

In order to reduce costs to authors who wish to order copies of their articles, this year we made off- prints available, in addition to the reprints that have traditionally been offered for articles published in the Review. Offprints are created from actual journal pages (extra copies are printed to permit this), cut along the gutter edge and stapled close to the inner edge. Reprints are printed on heavy, glossy $11 \times 17$ inch paper, which is folded and "saddle-stitched" (stapled in the fold) to resemble a booklet. Offprints are not quite as professional looking as reprints, but most people find them a completely acceptable alternative, at a considerably lower cost. For example, 100 copies of an offprint of any length up to 32 pages is $\$ 47$; reprints range in price from $\$ 101$ for 100 copies of an article of $9-12$ pages to $\$ 241$ for 100 copies of an article of 17-20 pages. Many authors are now ordering offprints rather than reprints and

\section{TABLE 8}

\section{Books Received, 1995-97, and Books Reviewed, 1996-97}

\begin{tabular}{|c|c|c|c|}
\hline \multirow[b]{2}{*}{ Field } & \multicolumn{2}{|c|}{ Books Received } & \multirow{2}{*}{$\begin{array}{c}\begin{array}{c}\text { Books Reviewed } \\
\text { or Scheduled for } \\
\text { Review }\end{array} \\
1996-97 \\
N(\%)\end{array}$} \\
\hline & $\begin{array}{c}\text { September 1995- } \\
\text { August } 1996\end{array}$ & $\begin{array}{c}\text { September 1996- } \\
\text { August } 1997\end{array}$ & \\
\hline $\begin{array}{l}\text { American Politics } \\
\text { and Public Policy }\end{array}$ & 639 & 421 & $83(19.7 \%)$ \\
\hline $\begin{array}{l}\text { Comparative } \\
\text { Politics }\end{array}$ & 647 & 551 & $107(19.4 \%)$ \\
\hline Political Theory & 327 & 256 & $60(23.4 \%)$ \\
\hline $\begin{array}{l}\text { International } \\
\text { Relations }\end{array}$ & 359 & 369 & $94(25.5 \%)$ \\
\hline Total & 1972 & 1590 & $344(21.6 \%)$ \\
\hline
\end{tabular}

we estimate the collective savings to our authors at close to $\$ 8,000$ per year.

Because offprints come from printed journal pages, for this system to work well we now begin each new article on a right-hand page (most readers prefer this system anyway). This reduces slightly the number of pages available for text in every issue. However, as reported last year (Finifter 1996), we had previously discontinued blank pages between sections of the Review in order to increase text pages. Being able to provide offprints has caused us to give back a few of those regained pages, but, considering the savings to authors (as well as the aesthetic advantage), the cost-benefit ratio seems very favorable.

\section{Book Review ${ }^{18}$}

Table 8 provides data on the books received from September 1995 to August 1997. The Book Review received more than 1,500 books last year, down from the nearly 2,000 books received in recent years. This probably reflects the withdrawal of many commercial presses from the academic book market. Scholarly books, and certainly the best scholarly books (as evidenced by the pattern of APSA book awards), are increasingly university press books.

Repeating past patterns, most books received are in American Politics and Comparative Politics; fewer books are received in International Relations and Political Theory. However, Table 8 also shows that a slightly higher percentage of books are reviewed in International Relations and Political Theory than in American Politics and Comparative Politics. Hence, there is a rough balance among published reviews in the four fields. Table 9 provides data on the books reviewed from September 1996 to September 1997 that, ignoring the inevitable fluctuations from issue to issue, confirms this point.

The political science book world as sampled from the Review is probably more diverse in subject matter and methodology than the political science article world as sampled from our major journals. The Book Review is thus able to provide its 
TABLE 9

Books Reviewed by Issue and Field, September 1996-September 1997

\begin{tabular}{lccrr}
\hline Issue & American & Comparative & Theory & IR \\
\hline September 1996 & $25 \%$ & 26 & 25 & 24 \\
& $(25)$ & $(26)$ & $(25)$ & $(24)$ \\
December 1996 & $34 \%$ & 33 & 25 & 8 \\
& $(31)$ & $(31)$ & $(23)$ & $(7)$ \\
March 1997 & $31 \%$ & 27 & 21 & 21 \\
June 1997 & $(28)$ & $(24)$ & $(19)$ & $(19)$ \\
& $28 \%$ & 24 & 20 & 28 \\
September 1997 & $(25)$ & $(22)$ & $(18)$ & $(25)$ \\
& $30 \%$ & 26 & 24 & 20 \\
& $(28)$ & $(24)$ & $(22)$ & $(18)$ \\
\hline
\end{tabular}

Note: Ns include books reviewed in review essays and both multiple and single book reviews. Percentages across; rows sum to $100 \%$.

readers with a wonderful cross-section of the discipline's scholarship. Perhaps this is why many of the Review's readers turn first to its book review section. In order to highlight this diversity, the Book Review has continued to publish review symposiums and review essays. Some of these essays discuss books that are currently of interest to a wide audience in the discipline. For example, the review symposium on Voice and Equality was designed to bring together Americanists and theorists. Other essays have exactly the opposite intention: They review a set of books that have recently appeared on an emerging topic of which many political scientists may be unaware. For example, Robert Bates reviewed a set of books that apply rational choice theory to comparative politics, an area where this approach is still unusual but is receiving an increasing amount of attention. Hence, the individual book reviews and the review essays complement the articles and allow the Review to cover the gamut of scholarship in our discipline.

\section{Concluding Remarks}

Readers are invited to comment on this report, or on any of the editorial procedures of the APSR. Please visit our web site at http:// www.ssc.msu.edu/ apsr/ where you will find the complete table of contents, including book reviews, of each issue as soon as we receive paging information from the printer (approximately one month before the printed version appears in readers' mailboxes). For each issue we also provide the complete text of the "Editor's Notes" (which contains the most up-to-date version of the Instructions to Contributors), the abstracts for each article and, for those articles containing them, a complete list of tables and figures for each issue. Our web site also contains biographical and other information about our Editorial Board and staff, information about our review procedures, and the list of scholars (approximately 1,000 last year) who reviewed for us in each volume year. We continue to try to develop additional ways to make the web site useful to readers. You may also contact us by email at apsr@ssc. msu.edu.

\section{Notes}

1. Interns for 1996-97 were Sara C. Benesh, Christopher Butler, Kathleen Dowley, Mark S. Hurwitz, Elizabeth R. Kaufer, Matthew Kleiman, Brandon C. Prins, and Jeff Reno. Most have now gone back to their dissertation research and for 1997-98 we have new interns Jamie Carson, Bernard J. Dobski, Erik Herron, Andrew Padon, Lisa Shoichet, and Christopher Sprecher, with Kleiman continuing. The interns make major contributions to the review process. The Book Review Editor was assisted during 1996-97 by Eric Hirsch, Robert R. Lopez, and Dave Reilly.

2. This is a good opportunity to pay tribute to one of last year's reviewers, the late
Donald E. Stokes. Don reviewed an $A P S R$ submission just a few months before his death. On the day before the review was due, he called the $A P S R$ office to assure me that he was planning to send it by Federal Express later in the day. Since nothing in our 37-year acquaintance (Don was my very first teacher in graduate school at the University of Michigan in 1959, and I one of his first students) had led me to think his review would come in on time, this struck me immensely funny and we had a wonderful chat about how things were going at the Review (and how to encourage reviewers to respond on time). Don was pleased that both he and his daughter Susan were reviewing for the $A P S R$, and that it was being edited by a former student. He was a wonderful reviewer, as befits a true scholar, and a generous and inspiring teacher who helped me understand, among many other things, that being a young woman from Brooklyn was not an insurmountable impediment to a career in political science.

3. I am very grateful for the skill of our data processing consultant, Paul S. Wolberg, who developed our database system and the programming to produce the tables and other data mentioned in this report.

4. In general, publicity seemed to have been adequate. We received only two or three inquiries about the moratorium that indicated some confusion, i.e., from potential authors who thought the office was going to be closed during the moratorium period or who thought it extended for the entire summer.

5 . These data suggest that if the summer moratorium had not been instituted, the total number of submissions for the year would have increased to approximately 567 , which would have been an increase in total submissions of $6.4 \%$ over last year.

6. The "small N" papers are not quantitative but are not properly classified as interpretive. In general, their authors compare a small number of units (e.g., several urban areas or countries) with hypothesis or theory testing or development rather than description as the goal. Some of these can also be thought of as "case studies." This code was first introduced in the fall of 1996.

7. Again, the change in coding of formal theory papers complicates analysis of longterm trends. However, this change can lead only to increases in the relative proportion of papers classified in American Politics, Comparative Politics, and International Relations. Therefore, it seems clear that American Politics manuscripts do not dominate the Review to the extent they once did.

8. By the same token, some awaiting decisions may turn out to have shorter than average turnaround.

9. In editorial parlance, these are "redundant publications." Some are rather blatantly duplicative; e.g., we occasionally receive papers that contain tables, figures, and/or extensive amounts of text that duplicate exactly material in a prior publication of the author. Such cases are sometimes found when an intern searches the literature for potential reviewers who have done similar research only to find an article by the author that appears extremely similar to the submission; at other times we are told about similar papers by reviewers. 
10. My goal is actually for all APSR manuscripts to have lower than average turnaround time. I would be happy to provide a practice data set for any methodologist working on a statistic that would be useful for this purpose, although confidentiality and anonymity considerations would prevent me from later making the data set available for replication purposes.

11. While the physical space available in journals with different page sizes is not easy to compare, and the Review has a much larger page size than most other political science journals, it is nevertheless interesting to note that in response to increasing submissions, the American Joumal of Political Science (official journal of the Midwest Political Science Association) added 100 pages beginning with the 1997 volume.

12. Papers that went originally to the $A P S R$ office at Rochester are omitted because we did not merge the Rochester computer database into ours.

13. It is possible that the proportion of acceptances will soon rise as many reviews come in at the end of the summer, but potential acceptances take much longer to process than rejections. Calculating an analogous table limited to manuscripts submitted this year yields an acceptance rate of almost $9 \%$. Obviously, more of these manuscripts are still in process so this is a less stable figure than that presented in Table 6.

14. Typically, revisions are also sent to a new reviewer.

15. A manuscript "chain" is an original manuscript and, if it is revised and resubmitted, all its revisions.

16. Obviously, in all fields numerous papers are under review and being prepared for revision, so numbers will have changed even before this table is printed.

17. Elizabeth Johnston, the Review copy editor, reads with intelligence and helps authors state their ideas in the clearest possible way. Harriett Posner, our Director of Manuscript Processing and Production, reviews copy editing with authors and resolves any difficulties. Spontaneous correspondence from authors testifies to the exceptionally fine work they both do. Their efforts have also contributed to a marked improvement in the $R e$ view's readability index (currently at about 45 years of education, but previously even higher).

18. The Book Review section of this report was written by Mark Lichbach and data were provided by his office.

\section{References}

Finifter, Ada W. 1996. "Report of the Managing Editor of the American Political Science Review, 1995-96." PS: Political Science \& Politics 29(4): 758-68.

Patterson, Samuel C., John M. Bruce, and Martha Ellis Crone. 1991. "The Impact of the American Political Science Review." PS: Political Science \& Politics 24(4): 765-74.

Powell, G. Bingham, Jr. 1995. "Report of the Managing Editor of the American Political Science Review, August 30, 1995." PS: Political Science \& Politics. 28(4): 764-69.

\section{visit APSANet ...}

\section{Departments}

Grants \&

Fellowships

\section{Upcoming}

Conferences

\section{Journals}

Related

Organizations

\section{Membership}

Awards

Publications

And More...

\section{the American Political Science Association On-line.}

Visit APSANet and you'll find the latest information on APSA programs and actitivies. Applying for an APSA Small Research Grant? Need to renew your membership? Ordering a publication? Try it on-line. Its quick and its easy!

Attending the 1998 Annual Meeting in Boston? Visit APSANet for up-to-date information on hotels, airfare, and special programs, including the second Ithiel de Sola Pool Lecture. Be sure to register early via the on-line preregistration form. In the coming months look for information on short courses, the annual chair's conference, and the Association's Awards Ceremony.

The Association's site is a work in progress and we are interested in hearing about what you would like to see. Send your comments to apsa@apsanet.org.

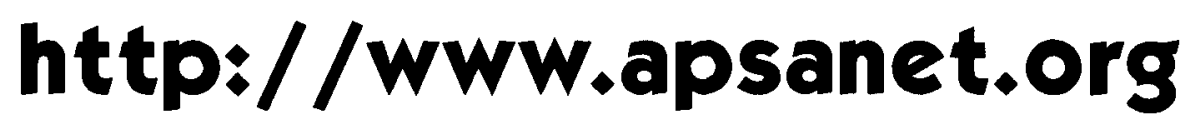

